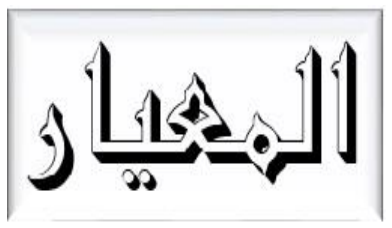

Al Mi'yar

Vol. 4, No. 1, April 2021

P-ISSN: 2620-6749, E-ISSN: 2620-6536

DOI: $10.35931 / a m . v 4 i 1.474$

Naskah diterima: 13-01-2021

Direvisi: 14-02-2021

Disetujui: 01-03-2021

\title{
REALISASI PENGAJARAN BAHASA ARAB MELALUI MEDIA AUDIO VISUAL PADA MAHASISWA CLUB BAHASA ARAB IAIN PONTIANAK
}

\author{
Moh Yusuf Hidayat \\ IAIN Pontianak \\ Email: yusufhidayat@iainptk.ac.id
}

\begin{abstract}
This research aimed to determine the form of Arabic language learning realization through audio visual media on Arabic club students in IAIN Pontianak. It focused on the Arabic learning materials and whether this activity can improve the competence of Arabic club students in learning Arabic language which is expected on KKNI Arabic language for university. This research used qualitative approach using descriptive data through interview from informants in IAIN Pontianak. The result revealed that Arabic language learning realization through audio visual media on Arabic club students carried out by mentors in IAIN Pontianak is not more than the realization of learning pattern which determine on the implementation of the Arabic lesson plan and syllabus, and than the materials taught has referred to the standard of competence expected in university on KKNI Arabic language, and teaching realization can measure the competence of Arabic club students expected in university on KKNI Arabic language.
\end{abstract}

Keywords: Arabic Language, Audio Visual Media, IAIN Pontianak

\section{PENDAHULUAN}

Pendidikan adalah proses yang di dalamnya terdapat suatu kegiatan yang terinci, terencana dan terprogram guna mencapai tujuan proses pembelajaran seperti aspek kognitif, afektif dan psikomotorik ${ }^{1}$. Unit kegiatan mahasiswa yang juga mengoptimalkan ketiga aspek tersebut adalah club bahasa Arab IAIN Pontianak.

1 Umi Machmudah and Abdul Wahab Rosyadi, Active Learning Dalam Pembelajaran Bahasa Arab (Malang: UIN-Malang Press, 2008), 21. 
Moh Yusuf Hidayat: Realisasi Pengajaran Bahasa Arab Melalui Media Audio Visual Pada Mahasiswa Club Bahasa Arab Iain Pontianak

Pembelajaran bahasa Arab dalam kurikulum KKNI adalah suatu proses pengembangkan dan pembinaan kemampuan berbahasa Arab aktif maupun pasif serta menumbuhkan sikap positif terhadap bahasa itu². Kemampuan berbahasa Arab sangatlah penting dalam rangka memahami ajaran Islam, baik al Qur'an dan Hadits serta kitab berbahasa Arab yang berkenaan dengan kajian keislaman³.

Dalam pembelajaran bahasa Arab, kita mengenal empat keterampilan berbahasa yaitu keterampilan menyimak, berbicara, membaca dan menulis ${ }^{4}$. Keempat keterampilan berbahasa ini diajarkan kepada mahasiswa dengan berbagai macam variasi agar mahasiswa tidak jenuh dalam mempelajari bahasa Arab. Menurut Abdul 'Alim Ibrahim ${ }^{5}$ syarat minimal bagi dosen dalam mengajarkan keterampilan berbahasa adalah pada penguasaan materi tentang keterampilan berbahasa serta dapat mengajarkannya kepada mahasiswa. ${ }^{6}$

Dalam pemaparan di atas disebutkan bahwa bahasa Arab yang diajarkan di perguruan tinggi berfungsi sebagai materi pengetahuan bahasa di samping sebagai alat komunikasi. Oleh karena itu mata kuliah bahasa Arab di perguruan tinggi merupakan bagian dari mata kuliah keagamaan secara keseluruhan7. Walaupun demikian, pembelajaran bahasa Arab di perguruan tinggi harus tetap berpedoman kepada prinsip-prinsip pembelajaran bahasa asing pada umumnya.

Secara khusus disebutkan bahwa pembelajaran bahasa Arab di perguruan tinggi bertujuan agar mahasiswa dapat menguasai perbendaharaan kosa kata bahasa Arab fusha sebanyak 10.000 kata dan ungkapan dalam bentuk dan pola kalimat dasar serta mahasiswa diharapkan dapat berkomunikasi dalam bahasa Arab dan dapat memahami bacaan-bacan sederhana dalam teks itu. ${ }^{8}$

2 Ahmad Fuad Affandi, Al Lugha al Arabiyah Fee Indunisiya (Riyadh: Daru Wujuh Lin Nasyri Wat Tauzi', 2015), 17.

${ }^{3}$ Fuad Affandi, 109.

${ }^{4}$ Rusydi Ahmad Thuaimah, Al Maharat al Lughawiyah Mustawayatuha Tadrisuha Shu'ubatuha (Madinatu nasr: darul fikri al arabi, 2009), 37.

${ }^{5}$ Abdul Alim Ibrahim, Al Muwajjih al Fanni Limudarrisil Lugha Alarabiyah (Mesir: Darul Ma'arif, 1968), 23.

${ }^{6}$ Rusydi Ahmad Thuaimah, Talim al Arabiyah Li Ghairin Nathiqina Biha Manahijuhu Waasalibuhu (Ribath: al munadhomah alislamiyah littarbiyah walulum watsaqafah, 1989), 71.

${ }^{7}$ Fuad Affandi, Al Lugha al Arabiyah Fee Indunisiya, 21.

${ }^{8}$ Fuad Affandi, 23. 
Moh Yusuf Hidayat: Realisasi Pengajaran Bahasa Arab Melalui Media Audio Visual Pada Mahasiswa Club Bahasa Arab Iain Pontianak

Unit club bahasa Arab merupakan unit kegiatan mahasiswa pada IAIN Pontianak yang mempersiapkan mahasiswa menjadi lebih terampil dalam berbahasa Arab dan memupuk pemahaman mahasiswa akan pentingnya bahasa Arab sebagai sarana memahami kitab suci al Qur'an, hadits dan buku kajian keisaman berbahasa Arab. Dalam rangka memahami aspek kebahasaan dalam lingkup ilmu keislaman, maka unit club bahasa Arab selalu melakukan upaya inovasi pembelajaran demi tercapainya tujuan yang diinginkan.

Untuk mengatasi masalah kebahasaan, maka club bahasa Arab IAIN Pontianak mengembangkan konsep pembelajaran bahasa melalui penggunaan media audio visual sebagai pengejawantahan dari pengembangan dari sumber belajar berbasis multi media dan diharapkan siap melatih dan mendidik lulusan madarash aliyah atau sederajat, untuk memperoleh pendidikan profesional dibidang pembelajaran bahasa Arab. Sebagaimana kita ketahui bahwa media dalam perspektif pembelajaran merupakan instrumen yang sangat strategis dalam ikut menentukan keberhasilan proses belajar mengajar sebab keberadaanya secara langsung dapat memberikan dinamika tersendiri terhadap peserta didik ${ }^{9}$.

Untuk menjembatani proses pembelajaran yang demikian, diperlukan media pembelajaran yang mempermudah peserta didik dalam menangkap pesan-pesan pendidikan yang disampaikan ${ }^{1}$. Berpijak pada batas@n diatas, terlihat bahwa kedudukan media pembelajaran memegang peranan yang sangat penting dalam mengantarkan peserta didik pada tujuan yang diinginkan ${ }^{1}$. Khususnya dalam pembelajaran bahasa Arab, media pembelajaran mutlak diperlukan demi pencapaian empat kemahiran berbahasa. Untuk menghindari pembelajaran yang masih sangat berpusat pada kemampuan pengajar, maka diperlukannya adanya dukungan teknologi terutama audio visual, hal ini bertujuan agar mahasiswa dapat mengikuti perkuliahan dan memiliki gambaran yang jelas tentang materi yang diajarkan. ${ }^{1}$

2

${ }^{9}$ Ahmad Khairi Muhammad Kadhim and Jabir Abdul Hamid jabir, Al Wasail at Ta'limiyah Walmanhaj (Cairo: Darun Nahdhah al arabia, 1997), 59.

1 Khairi Muhammad Kadhim0and Jabir Abdul Hamid jabir, 70.

1 Khairi Muhammad Kadhim ${ }^{1}$ and Jabir Abdul Hamid jabir, 125.

1 basyir Abdur Rahim Alkảlub, Alwasail at Ta'limiyah at Ta'alumiyah i'daduha Wa Thuruqu Istikhdamiha (beirut: daru ihya al ulum, 1986), 151. 
Moh Yusuf Hidayat: Realisasi Pengajaran Bahasa Arab Melalui Media Audio Visual Pada Mahasiswa Club Bahasa Arab Iain Pontianak

\section{METODE PENELITIAN}

Penelitian ini menggunakan pendekatan kualitatif dan penggunaan pendekatan kualitatif dipandang sebagai prosedur penelitian yang dapat diharapkan akan menghasilkan data deskriptif, berupa kata- kata tertulis atau lisan dari sejumlah orang dan prilaku yang diamati ${ }^{1}$, dan metode yang digunakan dalam penelian ini adalah metode diskriptif yaitu metode dalam meneliti status kelompok, suatu obyek, suatu set kondisi, suatu sistem pemikiran ataupun suatu kelas pristiwa pada masa sekarang1 .

Untuk mengumpulkan data berupa sudut pandang Warek III IAIN Pontianak, Kaprodi PBA, pembina club bahasa Arab berjumlah satu orang dan para mahasiswa yang tergabung menjadi anggota club bahasa Arab dengan melalui observasi dengan panduan observasi. Kemudian data dianalisis secara kualitatif untuk mendiskripsikan mengenai realisasi pembelajaran bahasa Arab melalui media audio visual pada mahasiswa club bahasa Arab IAIN Pontianak. ${ }^{1}$ 5

\section{HASIL PENELITIAN}

Hasil penelitian akan dipaparkan secara deskriptif analisis sesuai dengan fokus penelitian. Adapun deskripsi data yang peneliti paparkan adalah bentuk realisasi pengajaran bahasa Arab melalui media audio visual pada mahasiswa club bahasa Arab IAIN Pontianak yang diselenggarakan oleh unit club bahasa Arab adalah pertama perencanaan, dalam perencanaan ini pembina club bahasa Arab merumuskan program pengajaran dalam SAP dan silabus di dalam rumusan SAP dan silabus tercantum identitas materi, standar kompetensi, kompetensi dasar, materi pokok, straregi, indikator, penilaian, alokasi waktu dan referensi. Kedua pelaksanaan, dalam pelaksanaan ini mentor telah merancang sebuah model pengajaran yang berpusat pada anak (child contered) dan dalam hal ini keterlibatan mahasiswa serta peran aktif mereka sangat diutamakan. Suasana belajar harus melibatkan mahasiswa secara berkelanjutan, misalnya proses pengamatan, proses bertanya dan 2006), 4 .

1 Lexy J. Moleong, Metodolỏgi Penelitian Kualitatif (Bandung: PT Remaja Rosdakarya,

1 Ahmad Badar, Usulul Bahtsi Ilmi Wamanaijuhu (Kuwait: wakalatul matbuat Abdullah harami, 1972), 39.

1 Sugiyono Sugiyono, Metodé Penelitian Administrasi (Bandung: Alfabeta, 2009), 20. 
Moh Yusuf Hidayat: Realisasi Pengajaran Bahasa Arab Melalui Media Audio Visual Pada Mahasiswa Club Bahasa Arab Iain Pontianak

proses mempertanyakan, serta menjelaskan. Ketiga evaluasi, dalam proses ini mentor melakukan penilaian dari keempat kemahiran berbahasa diantaranya bagaimana mahasiswa trampil dalam menyimak, trampil berbicara, trampil menulis dan trampil membaca ${ }^{1}$. Tes yang diberikan berkaitan dengan materi bacaan yang disampaikan lewat pesan audio dan visual lewat penayangan vcd buku "al Arabiyah baina yadaika". Dan mentor juga melakukan evaluasi kemampuan mahasiswa dalam menyusun sebuah kalimat yang benar dalam bahasa Arab, dan waktu yang harus ia luangkan sekitar 20 menit.

Adapun materi-materi yang diajarkan melalui media audio visual Pada mahasiswa club bahasa Arab IAIN Pontianak adalah sebagai berikut: Pertama, hiwar tentang at tahiyyat wa at ta'aruf, qira'ah dengan mufradat tentang at tahiyyat wa at ta'aruf dan struktur kalimat yang mengandung harful istifham, kitabah dengan mufradat dan struktur kalimat yang dipelajari, kedua, hiwar tentang al usrah, qira'ah dengan mufradat tentang al usrah dan struktur kalimat yang mengandung harful istifham aina dan miin, kitabah dengan mufradat dan struktur kalimat yang dipelajari, ketiga, hiwar tentang as sakan, qira'ah dengan mufradat tentang as sakan dan struktur kalimat yang mengandung alfi'l dan maf'ul bihi, kitabah dengan mufradat dan struktur kalimat yang dipelajari.

Selanjutnya mentor menegaskan bahwa di setiap kompetensi dasar materi bahasa Arab mahasiswa dituntut untuk dapat bercakap, membaca dan menulis dalam bahasa Arab sesuai materi yang disampaikan berdasarkan kompetensi dasar pada tiap materi. Sehingga pada pelaksanaan evaluasi yang diselenggarakan pada akhir semester mentor dapat mengetahui sejauh mana seorang mahasiswa menguasai materi yang sudah diajarkan oleh mentor.

Untuk mengetahui apakah realisasi pengajaran bahasa Arab melalui media audio visual pada mahasiswa club bahasa Arab IAIN Pontianak dapat mengukur kompetensi yang diharapkan, penulis mendeskripsikannya berupa hasil nilai yang diambil dari beberapa aspek yang bercirikan empat kemahiran berbahasa dengan asumsi bahwa mahasiswa yang mendapat nilai dibawah angka 55 diklasifikasikan sebagai mereka yang belum trampil dalam

1 Fathi Ali yunus and Muharmmad abdur rauf asyekh, Al Marji' Fee Ta'lim al Lugha al Arabiyah Lil Ajanib Minan Nadhariyah Ilat Tatbiq (Cairo: Maktabah Wahbah, 2003), 157. 
Moh Yusuf Hidayat: Realisasi Pengajaran Bahasa Arab Melalui Media Audio Visual Pada Mahasiswa Club Bahasa Arab Iain Pontianak

berbahasa. Data ini peneliti peroleh dari mentor materi bahasa Arab, adapun nilainya sebagai berikut:

\section{Tabel 3. Rekapitulasi Nilai Aspek Kemahiran Berbahasa Materi Bahasa Arab Pada mahasiswa Club Bahasa Arab}

\begin{tabular}{|c|c|c|c|c|c|c|}
\hline \multirow[b]{2}{*}{ No } & \multirow[b]{2}{*}{$\begin{array}{c}\text { NAM } \\
\text { A }\end{array}$} & \multicolumn{4}{|c|}{ HASIL PENILAIAN SEMESTER I PBA } & \multirow[b]{2}{*}{ KETERANGAN } \\
\hline & & $\begin{array}{l}\mathrm{M} \\
\mathrm{E} \\
\mathrm{N} \\
\mathrm{D} \\
\mathrm{E} \\
\mathrm{N} \\
\mathrm{G} \\
\mathrm{A} \\
\mathrm{R} \\
\end{array}$ & $\begin{array}{l}\mathrm{B} \\
\mathrm{E} \\
\mathrm{R} \\
\mathrm{B} \\
\mathrm{I} \\
\mathrm{C} \\
\mathrm{A} \\
\mathrm{R} \\
\mathrm{A}\end{array}$ & $\begin{array}{l}\mathrm{M} \\
\mathrm{E} \\
\mathrm{M} \\
\mathrm{B} \\
\mathrm{A} \\
\mathrm{C} \\
\mathrm{A}\end{array}$ & $\begin{array}{l}\mathrm{M} \\
\mathrm{E} \\
\mathrm{N} \\
\mathrm{U} \\
\mathrm{L} \\
\mathrm{I} \\
\mathrm{S}\end{array}$ & \\
\hline 1 & $\mathrm{Z}$ & 86 & 81 & 81 & 81 & Tuntas \\
\hline 2 & $\mathrm{Mr}$ & 56 & 56 & 55 & 57 & $\begin{array}{l}\text { Kurang Menguasai Kosakata.Tdk Menguasai Struktur } \\
\text { Mubtada Khobar-Khobar Mubtada,Fi'il 'Amar Dan Dialog } \\
\text { Sederhana }\end{array}$ \\
\hline 3 & A & 77 & 70 & 75 & 75 & $\begin{array}{l}\text { Kurang Menguasai Struktur Khobar Muqoddam- } \\
\text { Mubtadamuakhkhor }\end{array}$ \\
\hline 4 & Res & 75 & 67 & 67 & 70 & Tuntas \\
\hline 5 & Der & 70 & 66 & 70 & 70 & Tuntas \\
\hline 6 & Dar & 90 & 88 & 80 & 88 & Tuntas \\
\hline 7 & Dan & 77 & 72 & 76 & 75 & Tuntas \\
\hline 8 & De & 77 & 70 & 75 & 75 & Tuntas \\
\hline 9 & $\mathrm{Di}$ & 85 & 80 & 79 & 80 & Tuntas \\
\hline 10 & $\mathrm{Hi}$ & 55 & 53 & 53 & 57 & $\begin{array}{l}\text { Kurang Menguasai Kosakata.Tdk Menguasai Struktur } \\
\text { Mubtada Khobar-Khobar Mubtada,Fi'il 'Amar Dan Dialog } \\
\text { Sederhana }\end{array}$ \\
\hline 11 & Mun & 60 & 60 & 60 & 60 & Tuntas \\
\hline 12 & Mat & 79 & 75 & 77 & 75 & Tuntas \\
\hline 13 & Nan & 79 & 75 & 78 & 75 & Tuntas \\
\hline 14 & Sur & 87 & 82 & 82 & 81 & Tuntas \\
\hline 15 & Ozi & 55 & 57 & 58 & 58 & $\begin{array}{l}\text { Kurang Menguasai Kosakata.Tdk Menguasai Struktur } \\
\text { Mubtada Khobar-Khobar Mubtada,Fi'il 'Amar Dan Dialog } \\
\text { Sederhana }\end{array}$ \\
\hline 16 & Em & 55 & 57 & 56 & 56 & $\begin{array}{l}\text { Kurang Menguasai Kosakata.Tdk Menguasai Struktur } \\
\text { Mubtada Khobar-Khobar Mubtada,Fi'il 'Amar Dan Dialog } \\
\text { Sederhana }\end{array}$ \\
\hline 17 & Rint & 57 & 57 & 57 & 55 & $\begin{array}{l}\text { Kurang Menguasai Kosakata.Tdk Menguasai Struktur } \\
\text { Mubtada Khobar-Khobar Mubtada,Fi'il 'Amar Dan Dialog } \\
\text { Sederhana }\end{array}$ \\
\hline 18 & Syar & 79 & 75 & 75 & 76 & Tuntas \\
\hline 19 & $\mathrm{Su}$ & 90 & 88 & 88 & 88 & Tuntas \\
\hline 20 & Sa & 60 & 59 & 59 & 60 & Tuntas \\
\hline 21 & Sisi & 85 & 80 & 78 & 80 & Tuntas \\
\hline 22 & Sa & 86 & 81 & 80 & 80 & Tuntas \\
\hline 23 & $\mathrm{~K}$ & 66 & 65 & 67 & 67 & Tuntas \\
\hline 24 & $\mathrm{Aj}$ & 65 & 60 & 55 & 55 & $\begin{array}{l}\text { Kurang Menguasai Kosakata,Struktur Kalimat Mubtada } \\
\text { Khobar-Khobar Mubtada }\end{array}$ \\
\hline 25 & $\mathrm{Ru}$ & - & - & - & - & - \\
\hline 26 & Ela & 54 & 55 & 54 & 55 & $\begin{array}{l}\text { Kurang Menguasai Kosakata,Struktur Kalimat Mubtada } \\
\text { Khobar-Khobar Mubtada }\end{array}$ \\
\hline
\end{tabular}


Moh Yusuf Hidayat: Realisasi Pengajaran Bahasa Arab Melalui Media Audio Visual Pada Mahasiswa Club Bahasa Arab Iain Pontianak

Dari paparan data diatas menunjukkan bahwa mahasiswa club bahasa Arab IAIN Pontianak yang terdiri dari 26 mahasiswa dan sebagian dari mereka dinyatakan telah trampil dalam empat kemahiran berbahasa (mendengar, berbicara, membaca menulis) serta terdapat beberapa orang dari mereka yang diklasifikasikan belum memenuhi syarat trampil dalam berbahasa Arab dengan baik dan benar.

Dari data yang ditunjukkan bahwa siswa yang berjumlah 19 siswa dari seluruh mahasiswa club bahasa Arab telah tuntas dalam penilaian aspek empat kemahiran berbahasa dan sisanya yaitu berjumlah 7 siswa dengan hasil nilai yang diberi warna kuning belum tuntas dalam penilaian aspek yang dimaksud.

\section{PEMBAHASAN}

Dari hasil analisis hasil deskripsi data dan temuan data yang telah dipaparkan sebelumnya bahwa bentuk realisasi pengajaran bahasa Arab melalui media audio visual pada mahasiswa club bahasa Arab IAIN Pontianak yang dilaksanakan pada materi bahasa Arab pada mahasiswa yang diselenggarakan di unit club bahasa Arab IAIN Pontianak.

Pertama perencanaan ${ }^{1}$, dalam perencanaan in̄i mentor club bahasa Arab merumuskan program pengajaran dalam SAP dan silabus, di dalam rumusan SAP dan silabus tercantum identitas mata kuliah, standar kompetensi, kompetensi dasar, materi pokok, straregi, indikator, penilaian, alokasi waktu dan referensi. Uraian komponen silabus sebagai berikut: standar kompetensi dan kompetensi dasar, materi pokok, dalam hal ini mentor memaparkan butirbutir bahan pengajaran yang dibutuhkan mahasiswa dan memaparkan tentang tahap-tahap yang harus dilakukan dalam merealisasikan pengajaran bahasa Arab melalui media audio visual diantaranya yang perlu diperhatikan adalah karakteristik media agar mentor dapat memilih media mana yang sesuai dengan kondisi dan kebutuhan. Sebagai contoh media audio visual, merupakan media auditif dan visualitif yang mengajarkan topik-topik

1 Charles W.L. Hill and Gareth R. Jones, Essentials of Strategic Management, Second (Mason: South - Western, 2009), 14. 
Moh Yusuf Hidayat: Realisasi Pengajaran Bahasa Arab Melalui Media Audio Visual Pada Mahasiswa Club Bahasa Arab Iain Pontianak

pembelajaran yang bersifat verbal dan non verbal seperti pengucapan (pronounciation) dan reading (membaca teks) bahasa asing ${ }^{1}$.

Pencantuman standar kompetensi merupakan bagian dari target yang dilakukan oleh mentor dalam rangka pencapaian kemampuan terstandar mahasiswa dalam setiap materi dalam koridor KKNI. Kompetensi yang perlu diupayakan tercapai adalah: (1) mahasiswa mampu melafalkan 10000 kosa kata (1250 kosa kata baru pada tiap semester) dan ungkapan bahasa Arab dengan makhraj dan intonasi yang baik dan benar, (2) mahasiswa mampu membaca dan memahami makna kata-kata, makna wacana, dan ungkapan/idiom yang berhubungan dengan kehidupan sehari-hari di lingkungan kampus, rumah, dan yang berhubungan dengan aqidah, ibadah, dan akhlaq, (3) mahasiswa mampu memahami susunan kalimat dengan struktur kalimat yang meliputi fa'il, maf'ul bih, mubtada', khobar mubtada', na'at man'ut, idlafah lafdhiyyah, serta adawat al-jar, (4) mahasiswa mampu menggunakan kata-kata, ungkapan dan susunan kalimat yang diajarkan dalam percakapan sederhana, (5) mahasiswa mampu menyusun kalimat-kalimat Arab dalam insya' muwajjah dengan kata-kata dan struktur kalimat yang diajarkan.

Disamping itu menurut Ahmad Hidayatullah Zarkasyi bahwa standar kompetensi adalah kompetensi atau kemampuan standar yang harus dicapai oleh mahasiswa untuk setiap mata kuliah ${ }^{1}$. Standar kompetensi untuk setiap mata kuliah ini biasanya sudah disebutkan dalam kurikulum.

Kedua pelaksanaan ${ }^{2}$, dalam pelaksanaan 9ini mentor telah merancang sebuah model pengajaran yang berpusat pada anak (child contered) dan dalam hal ini keterlibatan mahasiswa serta peran aktif mereka sangat diutamakan. Mengingat belajar adalah proses membangun gagasan atau pemahaman sendiri, maka menurut Umi Machmudah dan Abdul Wahab Rasyidi ${ }^{2}$ bahwa kegiatan belajar mengajar hendaknya memberikan kesempatan kepada

1 Jamal Ibn Abdul Aziz syarlian, Al Wasail at Ta'limiyah Wa Mustajadati Tiknulugiyah at Ta'lim (Riyadh: Maktabal Malik Fahd al Wathoniyah atsna an nasyr, 2001), 67.

1 Fuad Affandi, Al Lugha al Arabiyah Fee Indunisiya, 98.

2 Graham Kenny, Strategic Planning and Perfomance Management (Burlington: Elsevier, 2005), 200.

2 Machmudah and Abdul Wahab Rosyadi, Active Learning Dalam Pembelajaran Bahasa Arab, 27. 
Moh Yusuf Hidayat: Realisasi Pengajaran Bahasa Arab Melalui Media Audio Visual Pada Mahasiswa Club Bahasa Arab Iain Pontianak

peserta didik untuk melakukan hal itu secara lancar dan termotivasi. Suasana belajar yang diciptakan mentor harus melibatkan mahasiswa secara aktif, misalnya proses pengamatan, bertanya dan mempertanyakan serta menjelaskan. Dan pemanfatan audio visual (IT) sangatlah tepat sebagai saran pendukung dalam pelaksanaan pengajaran materi bahasa Arab, mentor materi bahasa Arab memanfaatkan media audio visual sebagai sarana yang mempermudah proses pengajaran untuk mencapai target kompetensi yang diinginkan. Disamping itu menurut Ahmad Khairi dan Jabir ${ }^{2}$ media pembelajaran adalah segala sesuatu yang dapat digunakan untuk menyalurkan pesan (bahan pembelajaran), sehingga dapat merangsang perhatian, minat, pikiran dan perasaan si belajar dalam kegiatan belajar untuk mencapai tujuan pembelajaran tertentu. Dari kutipan diatas menunjukkan bahwa dosen melakukan pelaksanaan pengajaran materi bahasa Arab dengan menggunakan media audio visual dalam rangka merangsang perhatian, minat, pikiran dan perasaan si pebelajar dalam kegiatan belajar di ruang kelas ${ }^{2}$, dalam pelaksanaan ini dosen telah merancang sebuah model pengajaran yang berpusat pada anak (child centered) dan hal ini keterlibatan mahasiswa serta peran aktif mereka sangat diutamakan. Peran aktif mahasiswa dalam proses membangun ide sendiri, hendaknya memberikan kesempatan kepada mereka untuk melakukan hal itu secara berkesinambungan ${ }^{2}$. kegiatan pembelajaran yang dilaksanakan oleh mentor harus melibatkan mahasiswa secara aktif, hal itu bisa dilihat dari kegiatan mengamati, bertanya dan sebagainya. Dan teknis pelaksanaanya sebagai berikut, pemanfaatan bahan yang ditampilkan melalui media audio visual dengan langkah-langkah sebagai berikut mentor akan menjelaskan topik bahasan terlebih dahulu sekitar 5 menit dalam sesi ini urun rembug dengan para mahasiswa perlu dilakukan agar keterlibatan mereka benar-benar ada dalam sesi appersepsi ${ }^{2}$, setelah itu memberpkan mufrodat yang berkaitan dengan materi judul yang akan dibahas, pelaksanaan ini memakan waktu sekitar 30 menit, kemudian setelah mufrodat diberikan

2 Khairi Muhammad Kadhỉm and Jabir Abdul Hamid jabir, Al Wasail at Ta'limiyah Walmanhaj, 121.

2 Melvin L. Silberman, Activę Learning 101 Cara Belajar Siswa Aktif (Bandung: Penerbit Nusamedia, 2009), 128.

2 Ibrahim, Al Muwajjih al Fantni Limudarrisil Lugha Alarabiyah, 55.

2 L. Silberman, Active Learning 101 Cara Belajar Siswa Aktif, 128. 
Moh Yusuf Hidayat: Realisasi Pengajaran Bahasa Arab Melalui Media Audio Visual Pada Mahasiswa Club Bahasa Arab Iain Pontianak

langkah selanjutnya adalah pembahasan inti materi dengan menampilkannya melalui media audio visual dalam bentuk hiwar, dalam hal ini mentor akan membimbing mahasiswa untuk bersama-sama melantunkan dan melafalkan kata demi kata seperti ditampilan media dalam bentuk audio dan visual, proses membutuhkan waktu yang cukup panjang kisaran 45 menit, kemudian setelah itu yang mentor lakukan adalah memberikan kepada mahasiswa untuk mencoba membaca pesan visual serta melafalkan ulang pesan-pesan tersebut sampai mereka fasih dan lancar dalam berkomunikasi, untuk ini waktu yang di gunakan sekitar 30 menit dengan menunjuk mahasiswa secara bergiliran satu persatu. Dan sesi terakhir dalam pelaksanaan ini mentor menampilkan seluruh mufrodat lewat visualisasinya serta meminta mahasiswa untuk melafalkan ulang dari pesan audio yang mereka dengar, dengan waktu sekitar 20 menit merasa cukup mengulangi sesi mufrodat.

Ketiga evaluasi ${ }^{2}$, dalam proses ini npentor melakukan penilaian dari keempat kemahiran berbahasa diantaranya bagaimana mahasiswa trampil dalam menyimak, trampil berbicara, trampil menulis dan trampil membaca. Tes yang diberikan berkaitan dengan materi bacaan yang disampaikan lewat pesan audio dan visual lewat penayangan vcd buku "al Arabiyah baina yadaika". Dan mentor juga melakukan evaluasi kemampuan mahasiswa dalam menyusun sebuah kalimat yang benar dalam bahasa Arab, dan waktu yang harus ia luangkan sekitar 20 menit. Disamping itu menurut Umi Machmudah dan Abdul Wahab Rasyidi ${ }^{2}$ bahwa fungsi evaluaşi melalui penilaian adalah sebagai alat strategi yang cukup menarik untuk mengukur dan mengetahui tingkat ketercapaian kompetensi oleh mahasiswa dalam kelas tertentu.

Dalam kompetensi berbahasa Arab lebih lebih ditekankan pada kompetensi dalam empat ketrampilan berbahasa yang dimaksud, karena dalam kegiatan berbahasa khususnya bahasa Arab mahasiswa tidak hanya dituntut mahir satu aspek saja ${ }^{2}$, akan tetapi 4 hal $^{8}$ yang harus dikuasai oleh mahasiswa

2 Ahmad Muradi, Bahasa Arab Dan Pembelajarannya Ditinjau Dari Berbagai Aspek (Yogyakarta: Pustaka Prisma, 2011), 247.

2 Machmudah and Abdul Wahab Rosyadi, Active Learning Dalam Pembelajaran Bahasa Arab, 167.

2 Ahmad Fuad Mahmud Ußyan, Al Maharat al Lughawiyah Maiyatuha Wa Tharaiqu Tadrisiha (Riyadh: Darul Muslim lin nasyri wat tauzi', 1992), 7. 
Moh Yusuf Hidayat: Realisasi Pengajaran Bahasa Arab Melalui Media Audio Visual Pada Mahasiswa Club Bahasa Arab Iain Pontianak

diantaranya adalah 1) Menyimak, ${ }^{2}$ mahasiswa mampu menafsirkan berbagai makna dalam teks lisan dengan beberapa variasi komunikasi dan konteks, 2) Berbicara, ${ }^{3}$ mahasiswa mampu ${ }^{0}$ mengungkapkan berbagai makna dalam berbagai teks lisan, 3) Membaca, ${ }^{3}$ mahasiswa mampu memahami berbagai makna yang dijumpai dalam berbagai teks tertulis, struktur teks serta ciriciri bahasanya, 4) Menulis, ${ }^{3}$ mahasiswa mampu²mengungkapkan makna secara tertulis yang sesuai dalam budaya bahasa yang digunakan.

Dari kutipan diatas dapat diketahui bahwa dalam realisasi pengajaran bahasa Arab melalui media audio visual pada mahasiswa club bahasa Arab IAIN Pontianak yang dilakukan oleh mentor materi bahasa Arab tidak lebih dari sekedar realisasi pola pengajaran yang menitikberatkan pada aspek pelaksanaan rancangan yang termaktub dalam SAP dan silabus.

Dari hasil deskripsi data dan temuan penelitian yang sudah dipaparkan pada bab sebelumnya maka materi-materi yang diberikan pada realisasi pengajaran bahasa Arab melalui media audio visual pada mahasiswa club bahasa Arab IAIN Pontianak sudah sepenuhnya merujuk pada standar kompetensi yang diharapkan pada jenjang perguruan tinggi. Adapun materi yang sudah dirumuskan oleh mentor materi bahasa Arab berdasarkan kurikulum KKNI sebagai berikut:

\section{Tabel 4. Buku Materi Bahasa Arab Club Bahasa Arab IAIN} Pontianak

\begin{tabular}{|c|c|}
\hline Kompetensi Dasar & Indikator \\
\hline $\begin{array}{l}\text { Bercakap, membaca, dan } \\
\text { menulis dalam bahasa Arab } \\
\text { tentang التحية والتعارف dengan struktur } \\
\text { kalimat dasar yang mengandung } \\
\text { أدوات الإستفهام }\end{array}$ & $\begin{array}{l}\text { - Melafalkan kosakata baru dengan baik } \\
\text { dan benar; } \\
\text { - Mempraktekkankan hiwar dengan baik } \\
\text { dan benar; } \\
\text { - Mempraktekkan materi hiwar secara } \\
\text { berpasangan; } \\
\text { - Menggunakan kosakata dalam kalimat } \\
\text { dengan tepat; } \\
\text { - Melakukan muhadatsah dengan struktur }\end{array}$ \\
\hline
\end{tabular}

$\begin{array}{lll}2 & \text { Fuad Mahmud Ulyan, 47. } & 9 \\ 3 & \text { Fuad Mahmud Ulyan, 85. } & 0 \\ 3 & \text { Fuad Mahmud Ulyan, 119. } & 1 \\ 3 & \text { Fuad Mahmud Ulyan, 155. }\end{array}$ 
Moh Yusuf Hidayat: Realisasi Pengajaran Bahasa Arab Melalui Media Audio Visual Pada Mahasiswa Club Bahasa Arab Iain Pontianak

\begin{tabular}{|c|c|}
\hline & $\begin{array}{l}\text { kalimat yang benar; } \\
\text { - Melafalkan qira'ah dengan baik dan } \\
\text { benar; } \\
\text { - Menjawab pertanyaan mengenai bahan } \\
\text { qira'ah dengan baik dan benar. } \\
\text { - Menulis kalimat-kalimat Arab melalui } \\
\text { imla' manqûl; } \\
\text { - Memanfaatkan penggunaan kosakata } \\
\text { dalam kalimat-kalimat yang disediakan; } \\
\text { - Menjawab pertanyaan dengan baik dan } \\
\text { benar; } \\
\text { - Menyusun rangkaian kalimat; } \\
\text { - Menyusun paragraf sederhana; }\end{array}$ \\
\hline $\begin{array}{l}\text { Bercakap, membaca, dan } \\
\text { menulis dalam Bahasa Arab } \\
\text { tentang } \\
\text { الأسرة dengan struktur } \\
\text { kalimat dasar yang meliputi } \\
\text { الإستفهام : اين, من }\end{array}$ & $\begin{array}{l}\text { - Melafalkan koakata baru dengan lafal } \\
\text { yang baik dan benar; } \\
\text { - Mempraktekkan hiwar dengan lafal dan } \\
\text { intonasi yang baik dan benar; } \\
\text { - Mempraktekkan hiwar secara } \\
\text { berpasangan; } \\
\text { - Menggunakan kosakata dalam kalimat } \\
\text { yang disediakan dengan tepat; } \\
\text { - Melakukan soal dan jawab dengan } \\
\text { kosakata dan struktur kalimat yang } \\
\text { diajarkan; } \\
\text { - Melafalkan materi qira'ah dengan } \\
\text { intonasi yang baik dan benar; } \\
\text { - Menjawab pertanyaan dengan baik dan } \\
\text { benar. } \\
\text { - Menulis kalimat-kalimat Arab melalui } \\
\text { imla' manqul; } \\
\text { - Menggunakan kosakata dengan tepat; } \\
\text { - Menjawab pertanyaan yang disediakan; } \\
\text { - Menyusun kalimat; }\end{array}$ \\
\hline 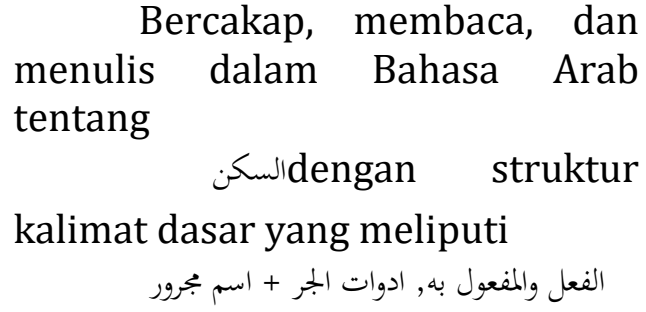 & $\begin{array}{l}\text { - Melafalkan kosakata baru dengan baik } \\
\text { dan benar; } \\
\text { - Mempraktekkan materi hiwar dengan } \\
\text { lafal yang baik dan benar; } \\
\text { - Mempraktekkan materi hiwar secara } \\
\text { berpasangan; }\end{array}$ \\
\hline
\end{tabular}


Moh Yusuf Hidayat: Realisasi Pengajaran Bahasa Arab Melalui Media Audio Visual Pada Mahasiswa Club Bahasa Arab Iain Pontianak

\begin{tabular}{|c|c|}
\hline & $\begin{array}{l}\text { - Menggunakan kosakata dalam kalimat } \\
\text { yang disediakan dengan tepat; } \\
\text { - Melakukan tanya jawab terstruktur } \\
\text { dengan menggunakan kosakata dan } \\
\text { struktur kalimat yang diajarkan; } \\
\text { - Mengucapkan materi qira'ah dengan } \\
\text { intonasi yang baik dan benar; } \\
\text { - Menjawab pertanyaan tentang materi } \\
\text { qira'ah dengan baik dan benar. } \\
\text { - Menulis kalimat-kalimat Arab melalui } \\
\text { imla' manqul; } \\
\text { - Menggunakan kosakata dengan tepat } \\
\text { dalam kalimat yang disediakan; }\end{array}$ \\
\hline 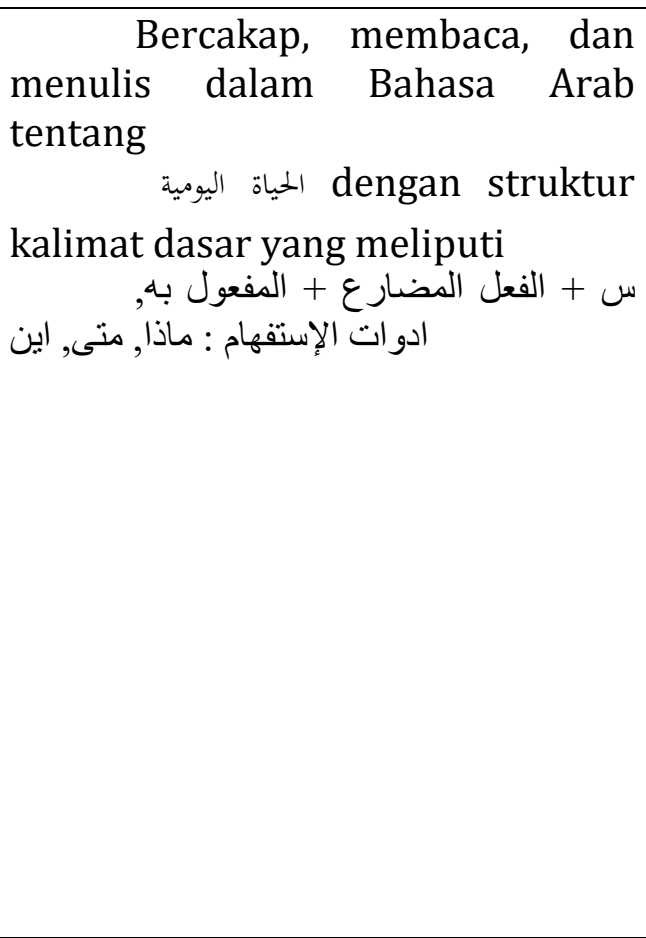 & $\begin{array}{l}\text { - Melafalkan kosakata baru dengan baik } \\
\text { dan benar; } \\
\text { - Mempraktekkan materi hiwar dengan } \\
\text { lafal yang baik dan benar; } \\
\text { - Mempraktekkan materi hiwar secara } \\
\text { berpasangan; } \\
\text { - Menggunakan kosakata dalam kalimat } \\
\text { yang disediakan dengan tepat; } \\
\text { - Melakukan tanya jawab terstruktur } \\
\text { dengan menggunakan kosakata dan } \\
\text { struktur kalimat yang diajarkan; } \\
\text { - Mengucapkan materi qira'ah dengan } \\
\text { intonasi yang baik dan benar; } \\
\text { - Menjawab pertanyaan tentang materi } \\
\text { qira'ah dengan baik dan benar. } \\
\text { - Menulis kalimat-kalimat Arab melalui } \\
\text { imla' manqul; } \\
\text { - Menggunakan kosakata dengan tepat } \\
\text { dalam kalimat yang disediakan; }\end{array}$ \\
\hline $\begin{array}{l}\text { Bercakap, membaca, dan } \\
\text { menulis dalam Bahasa Arab } \\
\text { tentang } \\
\text { kalimat dengan struktur } \\
\text { karar yang telah diajarkan }\end{array}$ & $\begin{array}{l}\text { - Melafalkan kosakata baru dengan baik } \\
\text { dan benar; } \\
\text { - Mempraktekkan materi hiwar dengan } \\
\text { lafal yang baik dan benar; } \\
\text { - Mempraktekkan materi hiwar secara } \\
\text { berpasangan; } \\
\text { - Menggunakan kosakata dalam kalimat }\end{array}$ \\
\hline
\end{tabular}


Moh Yusuf Hidayat: Realisasi Pengajaran Bahasa Arab Melalui Media Audio Visual Pada Mahasiswa Club Bahasa Arab Iain Pontianak

\begin{tabular}{|c|c|}
\hline & $\begin{array}{l}\text { yang disediakan dengan tepat; } \\
\text { - Melakukan tanya jawab terstruktur } \\
\text { dengan menggunakan kosakata dan } \\
\text { struktur kalimat yang diajarkan; } \\
\text { - Mengucapkan materi qira'ah dengan } \\
\text { intonasi yang baik dan benar; } \\
\text { - Menjawab pertanyaan tentang materi } \\
\text { qira'ah dengan baik dan benar. } \\
\text { - Menulis kalimat-kalimat Arab melalui } \\
\text { imla' manqul; } \\
\text { - Menggunakan kosakata dengan tepat } \\
\text { dalam kalimat yang disediakan; }\end{array}$ \\
\hline $\begin{array}{l}\text { Bercakap, membaca, dan } \\
\text { menulis dalam Bahasa Arab } \\
\text { tentang الصعاة dengan struktur } \\
\text { kalimat dasar yang mengandung : }\end{array}$ & $\begin{array}{l}\text { - Mengucapkan mufradat baru dengan } \\
\text { lafal yang baik dan benar; } \\
\text { - Mengucapkan materi hiwar dengan lafal } \\
\text { dan intonasi yang baik dan benar; } \\
\text { - Mendemonstrasikan materi hiwar } \\
\text { secara berpasangan; } \\
\text { - Menggunakan mufradat dalam kalimat- } \\
\text { kalimat yang disediakan dengan tepat; } \\
\text { - Melakukan tanya jawab dengan } \\
\text { mufradat dan struktur kalimat yang } \\
\text { diajarkan; } \\
\text { - Melafalkan bahan qira'ah dengan } \\
\text { intonasi yang baik dan benar; } \\
\text { - Menjawab pertanyaan/latihan tentang } \\
\text { kandungan bahan qira'ah dengan baik } \\
\text { dan benar. } \\
\text { - Menulis kalimat-kalimat Arab melalui } \\
\text { imla' manqul; } \\
\text { - Menggunakan mufradat dengan tepat } \\
\text { dalam kalimat-kalimat yang disediakan; } \\
\text { - Menjawab pertanyaan-pertanyaan yang } \\
\text { disediakan dengan baik dan benar; } \\
\text { - Menyusun kalimat dengan } \\
\text { menggunakan kata-kata yang } \\
\text { disediakan; } \\
\text { Menyusun paragraf sederhana dengan } \\
\text { ungkapan-ungkapan yang disediakan; }\end{array}$ \\
\hline
\end{tabular}


Moh Yusuf Hidayat: Realisasi Pengajaran Bahasa Arab Melalui Media Audio Visual Pada Mahasiswa Club Bahasa Arab Iain Pontianak

(Sumber: Buku Materi ajar dan Sistem Penilaian mata kuliah bahasa Arab prodi PBA Semester I).

Menurut M Abdul Hamid dkk $\mathbf{k}^{3}$, bahwa materi atau cỏntent adalah salah satu unsur penting dari keempat elemen mata kuliah dari tiga unsure lainnya, yaitu tujuan pembelajaran (learning objectives), strategi pembelajaran (instructional strategies), dan penilaian (evaluation). Secara garis besar, semua materi harus mengandung pengetahuan, keterampilan, dan sikap atau nilai yang harus dipelajari mahasiswa.

Materi bahasa Arab pada mahasiswa melalui media audio visual dipilih dengan tepat agar membantu mahasiswa dalam mencapai standar kompetensi dasar dan inti. Berbagai masalah yang muncul akibat pemilihan materi mata kuliah pembelajaran mencakup urutan, jenis, cakupan dan perlakuan (treatment) terhadap materi pembelajaran tersebut. Cakupan materi pembelajaran perlu diidentifikasi dengan tepat karena setiap cakupan materi pembelajaran memerlukan strategi, media, dan evaluasi yang berbeda.

Cakupan materi pembelajaran perlu diperhatikan agar tidak kurang dan tidak lebih ${ }^{3}$. Urutan (squence) perłu diperhatikan agar pembelajaran menjadi teratur ${ }^{3}$. Pemilihan secara ${ }^{5}$ tepat perlu dilakukan agar tidak salah mengajarkannya (misalnya perlu kejelasan apakah suatu materi harus dihafalkan, dipahami, atau diaplikasikan).

Kemudian dalam penyusunan materi pembelajaran ada beberapa prinsip yang perlu diperhatikan yaitu, prinsip relevan, konsisten, dan kecukupan, adapun penjabarannya adalah:

1. Prinsip keterkaitan (relevansi). Materi pembelajaran harus relevan dengan pencapaian standar kompetensi dan kompetensi dasar. Jika kemampuan yang diharapkan dikuasai pesrta didik berupa menghafal fakta, maka materi pembelajaran yang diajarkan harus berupa fakta.

2. Prinsip keajegan (konsistensi). Jika kompetensi dasar yang harus dikuasai oleh peserta didik ada tiga macam, misalnya kompetensi dasar yang harus dikuasai peserta didik adalah bercakap, membaca, dan menulis, maka

3 M Abdul Hamid, Uril Bảhruddin, and Bisri Mustofa, Pembelajaran Bahasa Arab Pendekatan, Metode, Strategi, Materi Dan Media (Malang: UIN-Malang Press, 2008), 69.

3 Hamid, Uril Bahruddin, and Bisri Mustofa, 104.

3 Ali yunus and Muhammad 5abdur rauf asyekh, Al Marji' Fee Ta'lim al Lugha al Arabiyah Lil Ajanib Minan Nadhariyah Ilat Tatbiq, 82. 
Moh Yusuf Hidayat: Realisasi Pengajaran Bahasa Arab Melalui Media Audio Visual Pada Mahasiswa Club Bahasa Arab Iain Pontianak

materi yang diajarkan juga harus meliputi tiga teknik yaitu bercakap, membaca, dan menulis.

3. Prinsip kecukupan artinya materi harus cukup dan memadai dalam membantu pesrta didik menguasai kompetensi dasar yang diajarkan. Materi tidak boleh terlalu sedikit ataupun terlalu banyak. ${ }^{3}$.

Dari kutipan diatas maka materi yang diajarkan pada pembelajaran materi bahasa Arab Melalui Media Audio Visual pada mahasiswa club bahasa Arab IAIN Pontianak sesuai dengan pedoman standar kompetensi berdasarkan kurikulum pada perguruan tinggi.

Dari deskripsi data dan temuan penelitian pada bab sebelumnya maka pembahasan dari fokus diatas adalah bahwa realisasi Pengajaran Bahasa Arab Melalui Media Audio Visual Pada Mahasiswa Club Bahasa Arab IAIN Pontianak dapat mengukur kompetensi yang diharapkan pada jenjang perguruan tinggi menurut KKNI Bahasa Arab. Karena dari 26 mahasiswa anggota club bahasa Arab IAIN Pontianak hanya 7 mahasiswa yang belum tuntas dalam realisasi Pengajaran Bahasa Arab Melalui Media Audio Visual Pada Mahasiswa Club Bahasa Arab IAIN Pontianak dan sisanya yaitu 19 mahasiswa dinyatakan tuntas dalam realisasi Pengajaran Bahasa Arab Melalui Media Audio Visual Pada Mahasiswa Club Bahasa Arab IAIN Pontianak tersebut sehingga bagi mahasiswa yang belum tuntas perlu mengikuti perbaikan (remedial).

Kemudian dalam penentuan ketuntasan mahasiswa, mentor mematok nilai hasil realisasi pengajaran mata kuliah Bahasa Arab dengan standar nilainya adalah 58. Nilai tersebut merupakan nilai patokan dasar ketuntasan yang penetapan ketuntasannya mencakup essensial, kompleksitas, daya dukung dan intake. Sehingga bagi mahasiswa yang nilai hasil realisasi pengajaran materi bahasa Arab adalah 58 maka mahasiswa itu dianggap tuntas.

Disamping itu dalam menetapkan SKBM (mastery learning). Ketuntasan belajar adalah tingkat/batas standar kompetensi yang harus dicapai oleh mahasiswa per materi adalah:

1. Nilai ketuntasan belajar maksimal/ideal adalah 100.

3 Abdul Hafidz Muhammad Salamah, Tasmim at Tadris (Riyadh: Darul Khirrij linnasyri wat tauzi', 2003), 154. 
Moh Yusuf Hidayat: Realisasi Pengajaran Bahasa Arab Melalui Media Audio Visual Pada Mahasiswa Club Bahasa Arab Iain Pontianak

2. Nilai ketuntasan belajar mahasiswa (pada pengetahuan, pemahaman konsep dan praktek), dinyatakan dalam bentuk bilangan bulat dengan rentang 0-100.

3. Perguruan tinggi dapat menetapkan Standar Ketuntasan Belajar Minimal (SKBM) di bawah nilai ketuntasan maksimal (100), namun perguruan tinggi harus merencanakan target ketuntasan dalam waktu tertentu untuk mencapai nilai Ketuntasan Belajar Maksimal, oleh sebab itu satu skor tes hanya dibandingkan dengan suatu skor batas kelulusan yang telah ditetapkan sebagai indikasi dari penguasaan content atau materi tertentu ${ }^{3}$.

4. Nilai SKBM di tetapkan pada awal tahun akademik untuk setiap mata kuliah pada semua kelas dan dievaluasi pada setiap semester.

5. Penentuan SKBM dilakukan melalui analisis ketuntasan belajar minimal pada setiap Kompetensi Dasar (KD) akan tetapi penentuan ketuntasan diberikan untuk setiap indikator pencapaian.

6. Penentuan SKBM setiap KD dimaksud, dilakukan melalui analisis indikator pencapaian (IP) pada KD terkait dan IP merupakan acuan pembuatan soal ujian. Dan soal ujian harus mampu mencerminkan pencapaian IP.

7. SKBM setiap KD merupakan rata-rata SKBM setiap indikator, indikator berfungsi sebagai kriteria ketuntasan belajar KD.

8. Mahasiswa dinyatakan telah mencapai ketuntasan belajar bila telah mencapai ketuntasan belajar untuk setiap indikator pada KD dimaksud.

9. SKBM setiap Standar Kompetensi (SK) marupakan rata-rata SKBM KD yang terkait.

Dari penjabaran kutipan diatas tampak jelas bahwa nilai ketuntasan mahasiswa bukan semata-mata hasil dari rekaan mentor materi bahasa Arab itu sendiri akan tetapi hasil dari SKBM yang sudah disepakati bersama oleh mentor materi bahasa Arab di club bahasa Arab IAIN Pontianak.

3 Fuad Affandi, Al Lugha al Arrabiyah Fee Indunisiya, 123. 
Moh Yusuf Hidayat: Realisasi Pengajaran Bahasa Arab Melalui Media Audio Visual Pada Mahasiswa Club Bahasa Arab Iain Pontianak

Akan tetapi peneliti menemukan bahwa realisasi Pengajaran Bahasa Arab Melalui Media Audio Visual Pada Mahasiswa club bahasa Arab IAIN Pontianak materi Bahasa Arab tidak mengadakan perbaikan (remedial) bagi mahasiswa yang belum tuntas dalam realisasi pengajaran bahasa Arab materi Bahasa Arab, hal itu dikarenakan mereka yang belum tuntas dapat mengikuti perbaikan pada semester berikutnya.

Dalam mempelajari materi pembelajaran untuk mencapai kompetensi dasar, di satu pihak sering dijumpai adanya mahasiswa yang mengalami kesulitan atau hambatan. Dalam menghadapi keadaan tersebut, penyusun materi pembelajaran perlu menyediakan suatu jenis materi pembelajaran, yaitu materi perbaikan (remedial). Materi pembelajaran remedial disusun lebih sederhana, lebih rinci, diberi banyak penjelasan dan contoh agar mudah ditangkap oleh mahasiswa.

Jadi dari hasil kutipan diatas tampak jelas bahwa realisasi Pengajaran Bahasa Arab Melalui Media Audio Visual Pada Mahasiswa club bahasa Arab IAIN Pontianak materi Bahasa Arab pada mahasiswa dapat mengukur kompetensi yang diharapkan pada jenjang perguruan tinggi menurut KKNI Bahasa Arab.

\section{SIMPULAN}

Adapun kesimpulan yang dapat diperoleh dari penelitian ini adalah dalam realisasi pengajaran bahasa Arab melalui media audio visual pada mahasiswa club bahasa Arab IAIN Pontianak yang dilakukan oleh mentor materi bahasa Arab tidak lebih dari sekedar realisasi pola pengajaran yang menitikberatkan pada aspek pelaksanaan rancangan yang termaktub dalam SAP dan silabus.

Materi yang diajarkan pada realisasi pengajaran bahasa Arab melalui media audio visual pada mahasiswa club bahasa Arab IAIN Pontianak sudah merujuk pada Standar kompetensi yang diharapkan pada jenjang perguruan tinggi menurut KKNI Bahasa Arab.

Realisasi pengajaran bahasa Arab melalui media audio visual pada mahasiswa club bahasa Arab IAIN Pontianak tahun dapat mengukur kompetensi yang diharapkan pada jenjang perguruan tinggi menurut KKNI Bahasa Arab, karena dari 26 mahasiswa yang mengikuti pengajaran bahasa Arab materi Bahasa Arab hanya 7 mahasiswa yang dikatagorikan belum 
Moh Yusuf Hidayat: Realisasi Pengajaran Bahasa Arab Melalui Media Audio Visual Pada Mahasiswa Club Bahasa Arab Iain Pontianak

tuntas dan 19 mahasiswa dinyatakan tuntas atau dapat mengukur kompetensi yang diharapkan pada jenjang perguruan tinggi menurut KKNI Bahasa Arab sehingga mahasiswa yang belum tuntas tersebut belum mencapai separuh dari jumlah mahasiswa club bahasa Arab IAIN Pontianak dan hal ini perlu untuk mengadakan perbaikan (remedial) bagi mahasiswa yang belum tuntas tetapi penulis menemukan bahwa realisasi pengajaran bahasa Arab melalui media audio visual pada mahasiswa club bahasa Arab IAIN Pontianak tahun 2019 materi bahasa Arab tidak mengadakan remedial bagi siswa yang belum tuntas dalam pengajaran bahasa Arab materi bahasa Arab, hal itu dikarenakan hasil nilai yang mereka peroleh dapat diperbaiki pada periode berikutnya pada materi yang sama.

\section{DAFTAR PUSTAKA}

Ahmad Thuaimah, Rusydi. Al Maharat al Lughawiyah Mustawayatuha Tadrisuha Shu'ubatuha. Madinatu nasr: darul fikri al Arabi, 2009.

-_- Talim al Arabiyah Li Ghairin Nathiqina Biha Manahijuhu Waasalibuhu. Ribath: al munadhomah alislamiyah littarbiyah walulum watsaqafah, 1989.

Ali yunus, Fathi, and Muhammad abdur rauf asyekh. Al Marji' Fee Ta'lim al Lugha al Arabiyah Lil Ajanib Minan Nadhariyah Ilat Tatbiq. Cairo: Maktabah Wahbah, 2003.

alkalub, basyir abdur rahim. Alwasail at Ta'limiyah at Ta'alumiyah i'daduha Wa Thuruqu Istikhdamiha. beirut: daru ihya al ulum, 1986.

Badar, Ahmad. Usulul Bahtsi Ilmi Wamanaijuhu. Kuwait: wakalatul matbuat Abdullah harami, 1972.

Fuad Affandi, Ahmad. Al Lugha al Arabiyah Fee Indunisiya. Riyadh: Daru wujuh lin nasyri wat tauzi', 2015.

Fuad Mahmud Ulyan, Ahmad. Al Maharat al Lughawiyah Maiyatuha Wa Tharaiqu Tadrisiha. Riyadh: Darul Muslim lin nasyri wat tauzi', 1992.

Hamid, M Abdul, Uril Bahruddin, and Bisri Mustofa. Pembelajaran Bahasa Arab

Pendekatan, Metode, Strategi, Materi Dan Media. Malang: UIN-Malang Press, 2008.

Ibn Abdul Aziz syarhan, Jamal. Al Wasail at Ta'limiyah Wa Mustajadati Tiknulugiyah at Ta'lim. Riyadh: Maktabal Malik Fahd al Wathoniyah atsna an nasyr, 2001.

Ibrahim, Abdul Alim. Al Muwajjih al Fanni Limudarrisil Lugha AlArabiyah. Mesir: Darul Ma'arif, 1968. 
Moh Yusuf Hidayat: Realisasi Pengajaran Bahasa Arab Melalui Media Audio Visual Pada Mahasiswa Club Bahasa Arab Iain Pontianak

J. Moleong, Lexy. Metodologi Penelitian Kualitatif. Bandung: PT Remaja Rosdakarya, 2006.

Kenny, Graham. Strategic Planning and Perfomance Management. Burlington: Elsevier, 2005.

Khairi Muhammad Kadhim, Ahmad, and Jabir Abdul Hamid jabir. Al Wasail at Ta'limiyah Walmanhaj. Cairo: Darun Nahdhah al Arabia, 1997.

L. Silberman, Melvin. Active Learning 101 Cara Belajar Siswa Aktif. Bandung: Penerbit Nusamedia, 2009.

Machmudah, Umi, and Abdul Wahab Rosyadi. Active Learning Dalam Pembelajaran Bahasa Arab. Malang: UIN-Malang Press, 2008.

Muhammad Salamah, Abdul Hafidz. Tasmim at Tadris. Riyadh: Darul Khirrij linnasyri wat tauzi', 2003.

Muradi, Ahmad. Bahasa Arab Dan Pembelajarannya Ditinjau Dari Berbagai Aspek. Yogyakarta: Pustaka Prisma, 2011.

Sugiyono, Sugiyono. Metode Penelitian Administrasi. Bandung: Alfabeta, 2009.

W.L. Hill, Charles, and Gareth R. Jones. Essentials of Strategic Management. Second. Mason: South - Western, 2009. 